\title{
Engagement with dietary fibre and receptiveness to resistant starch in Australia
}

\author{
Philip Mohr*, Sinéad Quinn, Matthew Morell and David Topping \\ CSIRO Food Futures National Research Flagship, PO Box 10041 Adelaide BC, SA 5000, Australia
}

Submitted 24 September 2009: Accepted 4 March 2010: First published online 21 April 2010

\begin{abstract}
Objective: To investigate community engagement with the health benefits of dietary fibre (DF) and its potential as a framework for the promotion of increased consumption of resistant starch (RS).

Setting: A nationwide postal Food and Health Survey conducted in Australia by CSIRO Human Nutrition.

Subjects: Adults aged 18 years and above, selected at random from the Australian Electoral Roll ( $n$ 849).

Design: A cross-sectional design was employed to analyse ratings of (i) the importance of various RS health and functional claims and (ii) receptiveness to different foods as RS delivery vehicles, according to the respondents' level of fibre engagement as classified under the Precaution Adoption Process Model (PAPM) of Health Behaviour.

Results: There was a high level of recognition (89.5\%) of DF as being important for health. Significant gender differences were found for ratings of RS attributes and RS delivery options. Women were both more fibre-engaged than men and more receptive than men to RS and its potential benefits. Ratings of the acceptability of several foods as means of delivering RS revealed a general preference for healthy staples over indulgences, with the margin between acceptability of staples and indulgences increasing markedly with increased fibre engagement. Conclusions: Application of the PAPM to awareness of DF reveals a ready-made target group for health messages about RS and pockets of differential potential receptiveness. The findings support the promotion of RS as providing health benefits of DF with the added reduction of risk of serious disease, its delivery through healthy staples and the targeting of messages at both fibre-engaged individuals and women in general.
\end{abstract}

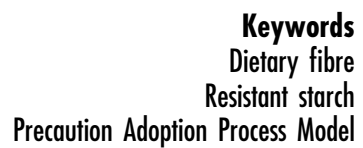

Keywords

Dietary fibre

Precaution Adoption Process Model
Global trends have seen a move away from diets high in complex carbohydrates and fibre towards diets that, while more varied, are much more energy-dense and higher in sugar and fats ${ }^{(1,2)}$. This 'nutrition transition" (1-4) is accompanied by an associated risk profile shift from nutrient deficiencies and transmissible infectious diseases as the primary cause of morbidity and premature mortality towards chronic conditions such as CHD, diabetes, obesity and certain cancers ${ }^{(5,6)}$. The trend is not specific to Western societies; the incidences of colorectal cancer and diabetes are increasing at disturbing rates, especially in developing and newly industrialised countries ${ }^{(7-10)}$. The public health challenge is that individuals, while aware of the implications of diet choice, continue to make food choices that can result in inadequate intakes of important nutrients such as dietary fibre (DF) ${ }^{(11-13)}$. In Australia, while the average daily intake of fibre is quite high $(27-28 \mathrm{~g} / \mathrm{d})^{(14)}$, incidence of chronic diseases such as diabetes continues to rise ${ }^{(15)}$, and colorectal cancer is ranked consistently as one of the most common newly reported cancers each year ${ }^{(16)}$. Recent data suggest a possible reason. While generally recognised fibre components such as non-starch polysaccharides (NSP) are important for human health, other lesser-known components of fibre may be equally significant ${ }^{(17)}$. Of these, resistant starch (RS) is emerging as a fibre fraction that has particular potential for lowering disease risk.

The definition of DF has undergone a number of refinements in past decades as more becomes known about its physiological properties (e.g. digestion, absorption and effects on health) ${ }^{(18)}$. DF, as defined by Food Standards Australia and New Zealand (FSANZ), is that fraction of the edible parts of plants or their extracts, or synthetic analogues, that are resistant to digestion and absorption in the small intestine, usually with complete or partial fermentation in the large intestine. DF includes polysaccharides, oligosaccharides (degree of polymerisation $>2$ ) and lignins, and promotes one or more of the following beneficial 
physiological effects: laxation, reduction in blood cholesterol and modulation of blood glucose ${ }^{(19)}$. However, not all of the non-digestible carbohydrates fractions classified as DF are able to perform these health benefits to the same extent $^{(18)}$. Although NSP work through physical bulking, preventing constipation, they may be less effective in protecting against other conditions such as colorectal cancer. This protective effect may in fact be due to other components of DF, most notably $\mathrm{RS}^{(18)}$.

Dietary starch was originally thought to undergo complete breakdown in the small intestine, but it is now known that a proportion - termed RS - escapes digestion in the small intestine and becomes available for fermentation by microflora present in the large bowel ${ }^{(14,20-22)}$. The protective mechanism of RS lies with its relatively high fermentability that enhances short-chain fatty acid - specifically butyrate - production and gives it prebiotic properties $^{(17)}$. There is growing experimental and epidemiological evidence for a role for RS in the reduction of risk and/or the management of a number of major health issues and risk factors, particularly those chronic diseases typically associated with the global changes seen in dietary intakes $^{(1-4,18,23-25)}$. Thus, there seems to be a very good case for the health benefits of increased RS consumption. Although there are no official targets set for daily RS intake as there are for DF, estimated intake of RS in developed countries is quite low, ranging from $3-4 \mathrm{~g} / \mathrm{d}$ to $15-20$ $\mathrm{g} / \mathrm{d}^{(14,26-29)}$. In Australia, the mean intake of RS is estimated at $5 \cdot 3 \mathrm{~g} / \mathrm{d}$ for men and $5 \cdot 0 \mathrm{~g} / \mathrm{d}$ for women, well below the doses ( $20 \mathrm{~g} / \mathrm{d}$ and above) used in experimental feeding studies that have found beneficial health effects ${ }^{(14,28,30-32)}$.

Determining the most appropriate mechanisms to increase RS intake at the population level may be an emerging focus for public health intervention. Existing sources of dietary RS are foods such as unprocessed whole grains, legumes, unripe bananas, and the now relatively uncommon cooked-and-chilled preparations of pasta, rice or potatoes ${ }^{(26,33,34)}$. Availability issues may be addressed through the creation of novel grain cultivars, the modification of food processing practices and the development of new types of high RS starches, ultimately enabling the production of nutritionally enriched foods ${ }^{(5,33,35-38)}$. The greater challenge may lie in identifying the kind of message that is appropriate, the kinds of food that are likely to be most acceptable and the kinds of consumers to whom these messages and foods are likely to have greatest appeal; the development of successful health claims and the marketing of foods offering health benefits is not a simple matter ${ }^{(39)}$. In the case of RS, the task may be simplified by its relationship to DF, a nutrient that already enjoys a high level of consumption - and possibly therefore recognition - in Australia. The purpose of the present study was to explore the potential of using community engagement with DF as a framework for the promotion of RS.

The Precaution Adoption Process Model (PAPM) was used to characterise engagement with the concept of DF in the community. The PAPM is a stage model of behaviour $^{(40,41)}$ that has been applied successfully to the analysis of people's uptake of a number of health behaviours including osteoporosis prevention, colon cancer screening and prevention of weight gain ${ }^{(42-44)}$. The model consists of seven logically sequenced stages, from lack of awareness of an issue through to maintained action $^{(45)}$ (Fig. 1), and provides a basis for tailoring of messages to suit specific stage transitions ${ }^{(46)}$. For example, the messages appropriate to the promotion of awareness of a health issue among the unaware will be quite different from those that may assist the behaviour change of individuals who have decided to take action. The present application employed the PAPM as a basis for classifying people in terms of their level of engagement with DF and investigated the implications of this classification for receptiveness to RS health claims and food products. This is a novel application of the PAPM as a population segmentation framework for the exploitation of community engagement with a relatively familiar health concept or behaviour (DF consumption) in the promotion of a novel, related concept or behaviour (RS consumption). Also investigated were perceived barriers or potential aids to the consumption of DF and the perceptions of risk of serious illness of individuals at different levels of fibre engagement.

\section{Methods}

Data were obtained by means of the 2008 CSIRO Food and Health Survey (FHS), a national postal survey of adults, aged 18 years and above, selected at random from the Australian Electoral Roll. A total of 849 (40.4\%) of a possible 2104 completed survey forms were returned.

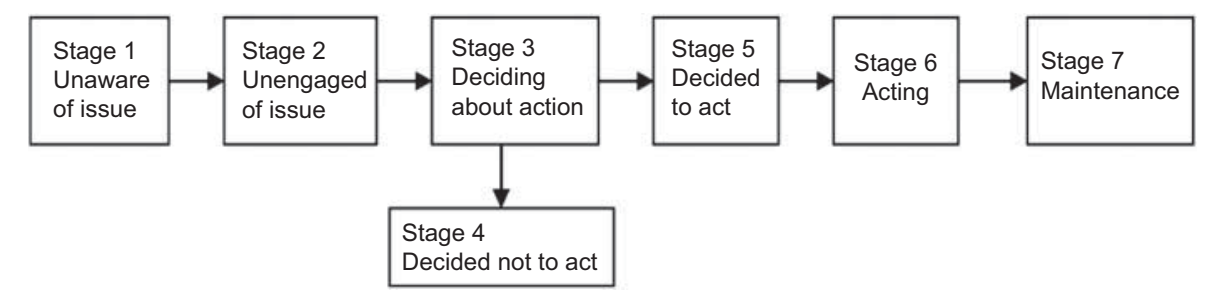

Fig. 1 Stages of the Precaution Adoption Process Model (PAPM; from Weinstein and Sandman ${ }^{(47)}$ ) 
Men $(40 \cdot 2 \%)$ and people below the age of 35 years were under-represented, hence the data were weighted by age and gender to reflect the distribution of these in the Australian population.

\section{Procedure}

In a section of the FHS titled 'Dietary fibre and resistant starch', respondents were asked whether or not they had ever heard about the health benefits of eating DF. Those who answered 'yes' were asked to indicate which of six phrases best described where they stood with regard to eating foods high in DF. These phrases were designed to represent level of fibre engagement corresponding to Stages 2-7, inclusive, of the PAPM, following the algorithm used by Weinstein and Sandman ${ }^{(47)}$. The phrases were never thought about it; thought about it but undecided; decided against it; decided to do it; doing it; and been doing it for years now. Next, these participants were invited to report any factors that made it difficult for them to consume enough DF and factors that would make it easier. These questions were used to identify barriers to fibre consumption, a factor which, according to the PAPM, may have implications for transition from Stage 5 (decided to act) to Stage 6 (acting).

The remainder of this section was about RS. Participants were asked to indicate whether or not they had ever heard about health benefits of eating RS. There followed a block of text under the title 'Some facts about resistant starch', which described RS in terms of its similarity to fibre and identified common sources and a number of attributes, including possible health benefits.

Next, participants were asked to rate the importance of each of the ten attributes as a reason for increasing their intake of RS in food. Attributes were derived from the preceding description of RS and covered the following.

- Health-related benefits (four items): improvement of digestive function; offering bealth benefits of fibre; aiding satiation; and lowering the glycaemic index (GI) of foods.

- Reduction of risks to health (four items): bowel cancer; bowel disease; diabetes; and obesity.

- Sensory and food production characteristics (one item each): no noticeable taste or texture; and replaces something that is often lost during food processing and preparation.

Ratings were made on a seven-point scale with extremes labelled Not at all important to me and Very important to me. Finally, respondents were asked to rate the acceptability of each of ten foods as a means of achieving a recommended increase in levels of RS in their diet. Nine of these foods were presented in the format [food] with increased RS. These were white bread; cakes or biscuits; whole-grain bread; muffins, snack foods; breakfast cereals; pasta or noodles; crackers or crispbreads; and flour for home cooking. The tenth was eating beans, lentils or chickpeas. Ratings were made on a seven-point scale with extremes labelled Not at all acceptable and Completely acceptable.

In Section 6 of the survey, titled 'Your health', participants rated their perceived risk of developing diabetes, obesity and bowel or rectal cancer on a five-point scale with extremes labelled No risk and High risk.

\section{Analyses}

\section{Fibre engagement}

Level of fibre engagement was defined by responses to two items. The lowest awareness category consisted of participants who indicated that they had not heard about health benefits of eating DF. Membership of all other categories was defined by the remaining participants' responses to the question asking where they stood with regard to eating foods high in DF. Because of the very small number of participants ( $n$ 9) who indicated that they had decided against DF, this category was excluded from all subsequent analyses involving a measure of fibre engagement*. A standard multiple regression was used to examine the association of the demographic variables of gender, age, education level and income with fibre engagement (as a six-level continuous variable).

\section{Barriers to dietary fibre consumption}

The qualitative responses to the questions 'what makes it difficult' and 'what would make it easier' to consume enough DF were coded independently by two judges. Discrepancies between the two sets of coded data were resolved by a third judge by referring to the original data. Initially, themes were developed from a small subset of the sample ( $\sim 20 \%)$. These themes were then used to create a template for the coding of the remaining responses. For both questions, the resultant themes (nineteen difficulties and twenty aids) were collapsed into more general themes and examined in relation to gender and fibre engagement of respondents.

\section{Importance of resistant starch attributes}

Rated importance of health risk reduction was calculated as the mean of responses to the four items addressing risk of bowel cancer, bowel disease, diabetes and obesity (Cronbach's alpha $=0.94$ ). Similarly, rated importance of health benefits was calculated as the mean of responses to the four items addressing improvement of digestive function, offering health benefits of fibre, aiding satiation and lowering the GI of foods (Cronbach's alpha $=0 \cdot 88$ ). These scores and importance ratings of the other two RS attributes were each subjected to $6 \times 2$ ANOVA with fibre engagement level and gender as the grouping variables.

\footnotetext{
* The majority of these individuals indicated that they had decided against eating foods high in DF due to factors outside of their control, such as aversive physical reactions or medical conditions.
} 
Perceptions of disease risk

Perceived risk of disease was calculated as the mean response to three items measuring personal perceptions of developing the following illnesses and conditions: diabetes, obesity and bowel or rectal cancer. Responses were subjected to $6 \times 2$ ANOVA with fibre awareness level and gender as the independent variables.

\section{Acceptability of resistant starch foods}

Reponses to food acceptability ratings were subjected to an initial principal components analysis (Kaiser-MeyerOlkin measure of sampling accuracy $=0.90$ and Barlett's sphericity $P<0 \cdot 001$ ), which revealed two components with eigenvalues $>1$. Subsequent factor analysis using principal axis factoring with oblique rotation resulted in the identification of two correlated factors, which we named Staples and Indulgences. Factor scores were calculated as the means of the items that loaded primarily on a given factor. For staples, these were whole-grain bread, breakfast cereals, pasta or noodles, crackers or crispbreads, flour for cooking and beans, lentils or chickpeas. For indulgences, they were white bread, cakes or biscuits, muffins and snack foods. Acceptability of these groupings as delivery mechanisms for RS was subjected to a repeated measures ANOVA with vehicle type (Indulgences $v$. Staples) as the within-subjects factor and fibre engagement level and gender as between-subjects variables.

\section{Results}

\section{Fibre engagement}

Table 1 shows the population-weighted distribution of fibre engagement by gender. Although $10 \cdot 5 \%$ of participants stated that they had not heard of health benefits of DF (Stage 1: unaware), two-thirds of the overall sample reported regularly eating a diet high in DF (Stage 6: acting and Stage 7: maintenance). Multiple regression analysis for the prediction of level of fibre engagement (with the decided against category excluded) from demographic characteristics explained $16 \%$ of population variance. Fibre engagement was significantly predicted by increasing age $\left(\beta=0 \cdot 38, P<0 \cdot 001, \mathrm{sr}^{2}=0 \cdot 13\right)$, increasing education level $\left(\beta=0 \cdot 17, P<0 \cdot 001, \mathrm{sr}^{2}=0 \cdot 02\right)$ and being female rather than male $\left(\beta=0 \cdot 15, P<0 \cdot 001, \mathrm{sr}^{2}=0 \cdot 02\right)$, but not by income $(\beta=0 \cdot 07)$.

\section{Barriers to dietary fibre consumption}

As might be expected, similar themes emerged from participants' reports on perceived difficulties with and solutions to increasing their DF intake. These were inherent characteristics of fibre, lifestyle issues and factors outside their control such as medical conditions and labelling. Environmental or lifestyle factors such as time pressures, cost and limited availability were the most common perceived barriers (15.4\%), especially among women (17.7\%; men: $12 \cdot 6 \%)$. The most common solutions offered focused on changing the qualities of DF itself, such as the taste, texture and general aesthetics. Although this solution was very popular $(17 \cdot 6 \%)$, it was particularly so among men $(21 \cdot 3 \%$; women $15 \cdot 5 \%)$. Of the 849 participants, $376(44 \cdot 3 \%)$ shared their thoughts on this topic. Within that group, the highest response rates to these questions were found among those who had thought about eating foods high in fibre, but were still undecided (PAPM Stage 3: 68.4\%) and those who had decided to do it, but had yet to take action (PAPM Stage 5: $67 \cdot 6 \%$ )

\section{Resistant starch awareness}

A total of 126 people $(15 \cdot 7 \%)$ indicated that they had heard about the health benefits of RS.

\section{Importance of bealth risk reduction}

ANOVA revealed main effects for fibre engagement $(F(5,849)=10 \cdot 65, P<0 \cdot 001)$, gender $(F(1,849)=20 \cdot 28$, $P<0 \cdot 001)$ and the interaction of the two $(F(5,849)=$ $3 \cdot 18, P<0 \cdot 01)$ on rated importance of health risk reduction as a reason for increasing RS consumption. Figure 2 shows the pattern of responses.

\section{Importance of bealth benefits and otber resistant starch attributes}

There were main effects for fibre engagement and gender on rated importance of health benefits of $R S(F(5,853)=$ $22 \cdot 78, \quad P<0 \cdot 001$ and $F(1,853)=19 \cdot 73, P<0 \cdot 001)$, its replacement of something lost in food production $(F(5,846)=$ $23 \cdot 73, P<0 \cdot 001$ and $F(1,846)=7 \cdot 60, P<0 \cdot 01)$ and its lack of taste or texture $(F(5,846)=2 \cdot 29, \quad P<0 \cdot 05$ and $F(1,846)=6 \cdot 43, P<0 \cdot 05)$. Women rated all attributes significantly more highly than men as justification for increasing RS intake. There were no significant interactions. Figure 3 shows the relationship between fibre engagement and importance ratings. Ratings of importance

Table 1 Level of fibre engagement by gender (\%)

\begin{tabular}{|c|c|c|c|c|c|c|c|}
\hline & \multicolumn{7}{|c|}{ Level of fibre engagement } \\
\hline & $\begin{array}{l}\text { Never heard about } \\
\text { health benefits }\end{array}$ & $\begin{array}{c}\text { Never thought } \\
\text { about it }\end{array}$ & $\begin{array}{l}\text { Thought about it } \\
\text { but undecided }\end{array}$ & $\begin{array}{l}\text { Decided } \\
\text { against it }\end{array}$ & $\begin{array}{l}\text { Decided } \\
\text { to do it }\end{array}$ & Doing it & $\begin{array}{l}\text { Been doing it } \\
\text { for years now }\end{array}$ \\
\hline Male & $13 \cdot 30$ & $5 \cdot 11$ & $10 \cdot 52$ & $1 \cdot 13$ & $9 \cdot 92$ & $29 \cdot 92$ & $28 \cdot 19$ \\
\hline Female & $7 \cdot 78$ & $2 \cdot 82$ & $6 \cdot 02$ & 0.83 & $8 \cdot 37$ & $35 \cdot 16$ & $37 \cdot 05$ \\
\hline Total & $10 \cdot 47$ & 3.94 & $8 \cdot 21$ & 0.98 & $9 \cdot 13$ & $32 \cdot 61$ & $32 \cdot 73$ \\
\hline
\end{tabular}




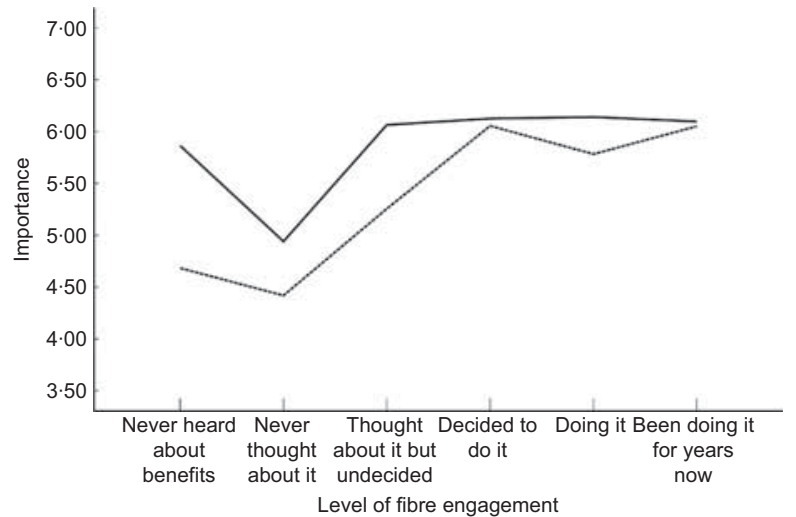

Fig. 2 Mean of the rated importance of risk reduction by fibre engagement and gender ( - , female; -.....-., male)

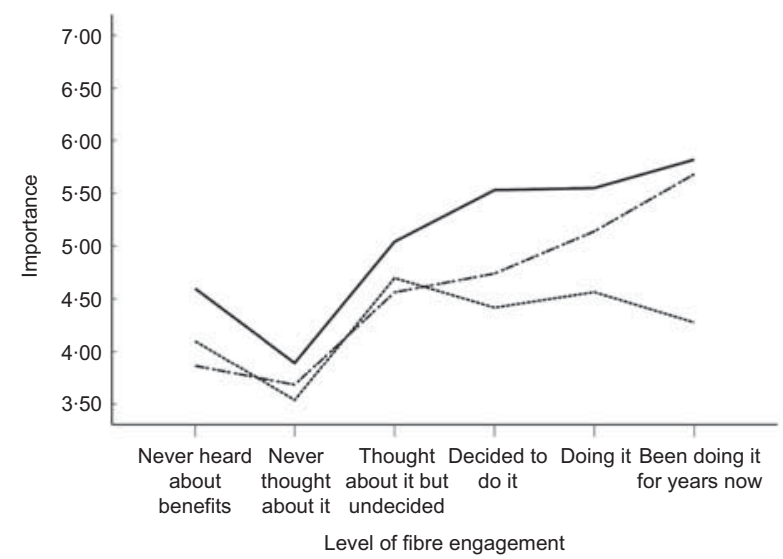

Fig. 3 Mean of the rated importance of resistant starch attributes by fibre engagement (- health benefits; ------replaces something lost in food processing; -.....-., no noticeable taste or texture)

of health benefits were highly correlated with those of health risk avoidance $(r=0 \cdot 80, P<0 \cdot 001)$.

\section{Perceptions of disease risk}

Main effects were found for fibre engagement on perceived personal risk of all three featured conditions: diabetes $(F(5,876)=3 \cdot 43, P<0 \cdot 005)$, obesity $(F(5,876)=$ $4 \cdot 44, P<0 \cdot 005)$ and bowel or rectal cancer $(F(5,876)=$ $3 \cdot 60, P<0 \cdot 005)$. Figure 4 shows the relationship between perceived risk and level of fibre engagement. A main effect for gender was found on perceived risk of diabetes $(F(5,876)=6 \cdot 37, \quad P<0 \cdot 05)$, mainly traceable to paradoxically elevated risk ratings of women in the 'never thought about it' stage of fibre engagement.

\section{Acceptability of food groupings}

A repeated measures ANOVA of acceptance of the two food groupings as vehicles for increasing RS in one's diet revealed a significant within-subjects effect for food grouping $(F(1,857)=93 \cdot 28, P<0 \cdot 001)$ and a significant

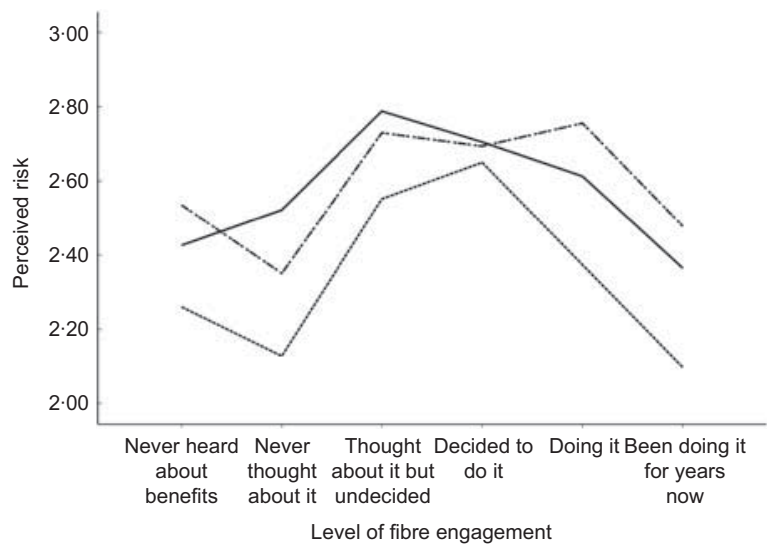

Fig. 4 Mean of the rated personal risk of serious lifestyle conditions by fibre engagement (-, diabetes; ------- , bowel or rectal cancer; -......, obesity)

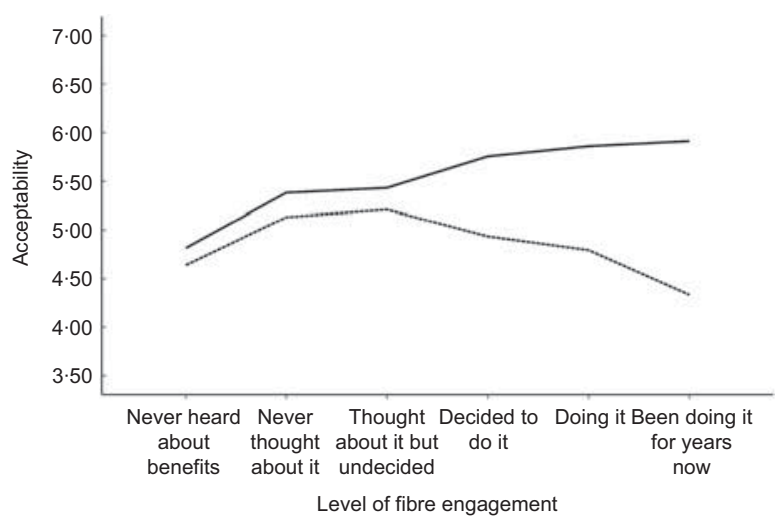

Fig. 5 Mean of the rated acceptability of food categories by fibre engagement (-, staples; -......-, indulgences)

interaction between food grouping and fibre engagement $(F(5,857)=17 \cdot 49, P<0 \cdot 001)$. Figure 5 shows the result. Overall, staples were more acceptable than indulgences, with the margin between the two increasing steeply with increasing fibre engagement. There was also a significant interaction between gender and food grouping $(F(1,857)=5 \cdot 33, P<0 \cdot 05)$, with women showing greater disapproval of indulgences. There was no three-way interaction.

\section{Discussion}

Although lack of public knowledge of the health benefits of fibre is often identified as a barrier for increasing consumption $^{(48)}$, the present data suggest that there is a high level of recognition among Australian adults that DF has a role to play in a healthy diet. Moreover, a substantial proportion of the adult population - women in particular - reported that they ate a diet high in fibre. Whether or not these self-reports are strictly accurate, they do indicate a high degree of engagement with the concept of DF. 
As a population estimate, the overall figure of $65 \%$ who reported having a fibre-rich diet may be inflated due to the possible over-representation of relatively healthconscious respondents to the survey. Nevertheless, independent evidence of average fibre consumption levels in Australia ${ }^{(14)}$ lends some credibility to figures of this order and supports the conclusion that the fibre message has a good foothold in the country.

Identification of the attitudinal, experiential and lifestyle factors that predict fibre engagement, though beyond the scope of the present report, is an appropriate subject for further research. Whatever the origins of people's awareness of the importance of DF, it clearly offers a framework for the promotion of increased consumption of the largely unrecognised fibre form, RS. This is important, as the concept of RS itself is relatively novel and its mode of action differs from the classical 'roughage model' of DF that focuses on its indigestibility. Application of the PAPM identified likely factors in this progression from awareness to consumption: namely, perceptions of health risk and importance of risk reduction and health benefits. The results of the present study are consistent with earlier work on the role of health risk perception in the intention to initiate risk reduction behaviour ${ }^{(49)}$. Figure 4 reveals a pattern of perceived risk that increases during the contemplation stages of the model and declines with the progression over subsequent stages once the decision to act has been made. What is worth noting is that the sense among the more fibre-engaged individuals of being at reduced risk of certain conditions is not accompanied by a lesser receptiveness to further health messages. For individuals in these latter stages, high importance was still attached to RS risk-reduction claims for the same conditions. In addition, perceptions of the importance of the set of health benefits, incorporating improvement of digestive function, satiation and GI as well as health benefits of fibre, were rated quite highly and showed a similar pattern of association with fibre engagement. For that apparent majority of the adult population who can be described as fibre-engaged category - those who report at least having decided to pursue a high-fibre diet - a number of RSrelated considerations appear to be salient.

Significant gender effects were found for ratings of RS attributes and RS delivery options. Women were both more fibre-engaged and more receptive than men to RS and its benefits. Moreover, the latter difference was not simply a function of the former. With fibre engagement controlled for statistically, women were still more receptive to health connotations of RS. Indeed, Fig. 2 reveals the ratings of the importance of reducing serious health risk by women in the fibre unaware and undecided categories to approximate those by women in the fibreengaged categories. Although not shown in Fig. 3, ratings of the importance of health benefits show a similar, though weaker, tendency. Observations of this kind, coupled with evidence of the central role that women play as managers of the family diet ${ }^{(50,51)}$, identify women as suitable targets for attempts to promote increased RS consumption in families as a preventive health measure.

The PAPM-based classification of respondents by level of fibre engagement also identified pockets of apparently low receptiveness to health messages, at least in the context of RS, as presented here. Those people who described themselves as never having thought about bealth benefits of fibre - the fibre-unengaged - showed the least interest in health considerations as justification for RS consumption. This pattern was evident for both men and women and prompts us to ask whether the main difference between this group of people and those in the seemingly lowest category of awareness - the unaware lies in the way they represent what is essentially a neglect of health-relevant information. The present data suggest that those who describe themselves as never having thought about health benefits of fibre may be making an active assertion of indifference. Such statements of indifference may be diagnostic of a group that poses a particular problem for public health intervention. By comparison, the pattern of responses of those professing a lack of awareness appears to offer some openness to the principle of intervention.

The relationships between fibre engagement and nonhealth attributes of RS are also informative. The endorsement of RS consumption as offsetting a deficiency of modern food production increased with increasing fibre engagement, thus implicitly linking the latter to a preference for naturalness in foods. The inoffensive sensory qualities of RS did not appear to be particularly persuasive to the fibre-engaged individuals and may have lacked salience at the lowest levels of awareness. Although texture was among the most commonly nominated obstacles to fibre consumption in responses to open-ended questions, it does not necessarily follow that it was perceived as an obstacle of particular importance. This is further borne out by the fact that, whereas changing texture was an option more commonly mentioned by men, its importance to personal consumption of RS was generally rated more highly by women. The open-ended questions provided further insight into the perceived obstacles of consuming enough DF. It is noteworthy that most of the respondents who identified perceived barriers to consumption were classified as at Stage 3 (undecided) or Stage 5 (decided, but not yet acting) of the PAPM. This is consistent with the observation from other research that when people actually take action they perceive fewer barriers $^{(44)}$.

Ratings of the acceptability of several types of foods as means of delivering RS - mostly as an implied enhancement of unspecified origin - revealed a general preference for healthy staples over indulgences. The staples group included foods with existing associations with fibre (e.g. breakfast cereals) and foods with less tangible health connotations (e.g. pasta and noodles). Indulgences 
included white bread as well as sweet and snack foods. Figure 5 illustrates the degree to which the preference for staples over indulgences increased with increasing fibre engagement. The uniformity of responses of the three top PAPM categories evident on some variables is noticeably absent here, with the margin between acceptability of staples and indulgences increasing markedly with increased fibre engagement. This is a pattern that - together with the increasing apparent preference for naturalness - associates membership of the top category of fibre engagement with a relative intolerance of ambiguity with regard to what constitutes healthy eating. Such intolerance may reflect a reliance on a fundamental classification of foods as generally healthy or generally unhealthy - a heuristic strategy that undoubtedly simplifies day-to-day dietary decision making. It is also suggestive of selfefficacy - the confidence of the most fibre-engaged individuals in their ability to pursue a dietary pattern not characterised by indulgences. This is in keeping with the enhanced sense of control suggested by their apparently reduced perception of being at personal risk of serious diseases, the avoidance of which they nevertheless continue to take seriously.

The favouring of healthy foods as a means of delivering additional health benefits is consistent with findings for functional foods of various types ${ }^{(39,52,53)}$. This identification of product-related attributes has been the focus of recent research and may prove important in the future development of products that better reflect consumers' expectations and further reduce barriers to acceptance ${ }^{(53,54)}$. The notion that consumers will be attracted by the prospect of achieving health benefits while still eating whatever they like may well have intuitive appeal to marketers. The present data, however, offer no grounds for confidence in any strategy seeking to promote RS through the notion of indulgences delivering health benefits.

\section{Conclusions}

The findings support the usefulness of the PAPM as a framework for understanding consumers' awareness of a given health issue and considerations associated with that issue. Application of the PAPM classifications to awareness of DF reveals, in the large population of fibreengaged individuals, a ready-made target group for health messages about RS and, among the relatively fibreunengaged, pockets of differential potential receptiveness. It offers insight into the kinds of considerations, including food types, which might have general or specific appeal and the special challenges posed by some groups. Findings support the promotion of RS as providing health benefits of DF with the added reduction of risk of serious disease, its delivery through healthy staples and the targeting of messages at both the fibre-aware and women in general.

\section{Acknowledgements}

The study was funded by the CSIRO Food Futures National Research Flagship. The authors have no conflict of interest. P.M. designed the study, conducted the statistical analysis and co-authored the manuscript. S.Q. co-authored the manuscript. D.T. and M.M. participated in revision of the manuscript. The authors gratefully acknowledge the assistance of Kate Fairweather-Schmidt for survey preparation and project management; Emily Brindal for data management and content analysis; Julie Syrette for data management; Heather Thomas and Jennie Cooper for data coding.

\section{References}

1. Drewnowski A \& Popkin BM (1997) The nutrition transition: new trends in the global diet. Nutr Rev 55, 31-43.

2. Drewnowski A (2000) Nutrition transition and global dietary trends. Nutrition 16, 486-487.

3. Popkin BM (2001) The nutrition transition and obesity in the developing world. $J$ Nutr 131, 871S-873S.

4. Popkin BM (1994) The nutrition transition in low-income countries: an emerging crisis. Nutr Rev 52, 285-298.

5. Topping DL, Morell MK, King RA et al. (2003) Resistant starch and health - Himalaya 292, a novel barley cultivar to deliver benefits to consumers. Starch 55, 539-545.

6. World Health Organization (2003) Diet, Nutrition and the Prevention of Chronic Diseases. Joint WHO/FAO Expert Consultation. WHO Technical Report Series no. 916. Geneva: WHO.

7. Ji B, Devesa S, Chow W et al. (1998) Colorectal cancer incidence trends by subsite in urban Shanghai, 1972-1994. Cancer Epidemiol Biomarkers Prev 7, 661-666.

8. Amos AF, McCarty DJ \& Zimmet P (1997) The rising global burden of diabetes and its complications: estimates and projections to the year 2010. Diabet Med 14, S1-S85.

9. World Health Organization (1997) The World Health Report. Geneva: WHO.

10. Center MM, Jemal A \& Ward E (2009) International trends in colorectal cancer incidence rates. Cancer Epidemiol Biomarkers Prev 18, 1688-1694.

11. Brennan CS (2005) Dietary fibre, glycaemic response, and diabetes. Mol Nutr Food Res 49, 560-570.

12. Australian Bureau of Statistics (1998) National Nutrition Survey: Nutrient Intakes and Physical Measurements, Australia. ABS Catalogue no. 4805.0. Canberra: ABS.

13. Henderson L, Gregory J, Irving K et al. (2003) The National Diet and Nutrition Survey: Adults Aged 19 to 64 Years. vol. 2: Energy, Protein, Carbohydrate, Fat and Alcobol Intake. London: The Stationery Office.

14. Baghurst PA, Baghurst KI \& Record SJ (1996) Dietary fibre, non-starch polysaccharides and resistant starch - a review. Food Aust S48, S1-S35.

15. Australian Bureau of Statistics (2009) National Health Survey: Summary of Results, 2007-08. Canberra: ABS; available at http://www.abs.gov.au/AUSSTATS/abs@.nsf/ $\mathrm{mf} / 4364.0 /$

16. Australian Institute of Health and Welfare \& Australasian Association of Cancer Registries (2007) Cancer in Australia: An Overview, 2006. AIHW Catalogue no. CAN 32. Canberra: AIHW.

17. Topping DL \& Clifton PM (2001) Short-chain fatty acids and human colonic function: roles of resistant starch and nonstarch polysaccharides. Physiol Rev 81, 1031-1064. 
18. Buttriss JL \& Stokes CS (2008) Dietary fibre and health: an overview. Nutr Bull 33, 186-2000.

19. National Health and Medical Research Council \& New Zealand Ministry of Health (2006) Nutrient Reference Values for Australia and New Zealand Including Recommended Dietary Intakes. Canberra: NHMRC, MoH.

20. Sanchez-Castillo CP, Hudson GJ, Englyst HN et al. (2002) The importance of dietary carbohydrates. Arch Latinoam Nutr 52, 321-335.

21. Lesmes U, Beards EJ, Gibson GR et al. (2008) Effects of resistant starch type III polymorphs on human colon mircobiota and short chain fatty acids in human gut models. J Agric Food Chem 56, 5415-5421.

22. Englyst HN, Kingman SM \& Cummings JH (1992) Classification and measurement of nutritionally important starch fractions. Eur J Clin Nutr 46, S33-S50.

23. National Health and Medical Research Council (2006) Nutrient Reference Values for Australia and New Zealand. Canberra: NHMRC.

24. Jenkins DJA, Kendall CWC, Axelsen M et al. (2000) Viscous and nonviscous fibres, nonabsorbable and low glycaemic index carbohydrates, blood lipids and coronary heart disease. Curr Opin Lipidol 11, 49-56.

25. Champ M, Langkilde AM, Brouns F et al. (2003) Advances in dietary fibre characterisation. 1. Definition of dietary fibre, physiological relevance, health benefits and analytical aspects. Nutr Res Rev 16, 71-82.

26. Asp NG, van Amelsvoort JMM \& Hautvast JGAJ (1996) Nutritional implications of resistant starch. Nutr Res Rev 9, 1-31.

27. Brighenti F, Casiraghi MC \& Baggio C (1998) Resistant starch in the Italian diet. Br J Nutr 80, 333-341.

28. Murphy MM, Spungen-Douglass J \& Birkett A (2008) Resistant starch intakes in the United States. J Am Diet Assoc 108, 67-78.

29. Elmstahl HL (2002) Resistant starch content in a selection of starchy foods on the Swedish market. Eur J Clin Nutr 56, 500-505.

30. Jenkins DJA, Vuksan V, Kendall CWC et al. (1998) Physiological effects of resistant starches on fecal bulk, short chain fatty acids, blood lipids and glycemic index. J Am Coll Nutr 17, 609-616.

31. Muir JG, Yeow EG, Keogh J et al. (2004) Combining wheat bran with resistant starch has more beneficial effects on fecal indexes than does wheat bran alone. Am J Clin Nutr 79, 1020-1028.

32. Cummings JH, Beatty ER, Kingman SM et al. (1996) Digestion and physiological properties of resistant starch in the human large bowel. BrJ Nutr 75, 733-747.

33. Muir JG, Young GP \& O'Dea K (1994) Resistant starch implications for health. Proc Nutr Soc Aust 18, 23-32.

34. Annison G \& Topping DL (1994) Nutritional role of resistant starch: chemical structure vs physiological function. Annu Rev Nutr 14, 297-320.

35. Brouns F, Kettlitz B \& Arrigoni E (2002) Resistant starch and 'the butyrate revolution'. Trends Food Sci Technol 13, 251-261.

36. Yue P \& Waring S (1998) Functionality of resistant starch in food applications. Food Aust 50, 615-621.

37. Sajilata MG, Singhal RS \& Kulkarni PR (2006) Resistant starch - a review. Compr Rev Food Sci Food Saf 5, 1-17.
38. Bird AR, Brown IL \& Topping DL (2000) Starches, resistant starches, the gut microflora and human health. Curr Issues Intest Microbiol 1, 25-37.

39. van Kleef E, van Trijp HCM \& Luning P (2005) Functional foods: health claim-food product compatibility and the impact of health claim framing on consumer evaluation. Appetite 44, 299-308.

40. Weinstein ND \& Sandman PM (1992) A model of the precaution adoption process: evidence from home radon testing. Health Psychol 11, 170-180.

41. Weinstein N (1988) The precaution adoption process. Health Psychol 7, 355-386.

42. Costanza ME, Luckmann R, Stoddard AM et al. (2005) Applying a stage model of behavior change to colon cancer screening. Prev Med 41, 707-719.

43. Wammes B, Kremers S, Breedveld B et al. (2005) Correlates of motivation to prevent weight gain: a cross sectional survey. Int J Behav Nutr Phys Act 2, 1.

44. Blalock SJ, DeVellis RF, Giorgino KB et al. (1996) Osteoporosis prevention in premenopausal women: using a stage model approach to examine the predictors of behavior. Health Psychol 15, 84-93.

45. Weinstein ND \& Sandman PM (2002) Reducing the risks of exposure to radon gas: an application of the precaution adoption process model. In Changing Health Behaviour: Intervention and Research with Social Cognition Models, pp. 66-86 [D Rutter and L Quine, editors]. Philadelphia, PA: Open University Press.

46. Sutton S (2005) Stage theories of health behaviour. In Predicting Health Behaviour, pp. 223-275 [M Conner and P Norman, editors]. New York: Open University Press.

47. Weinstein ND \& Sandman PM (2002) The precaution adoption process model and its application. In Health Behavior and Health Education: Theory, Research and Practice, 3rd ed., pp. 121-143 [K Glanz, BK Rimer and FM Lewis, editors]. San Francisco, CA: Jossey Bass.

48. Buttriss JL (1997) Food and nutrition: attitudes, beliefs, and knowledge in the United Kingdom. Am J Clin Nutr 65, 1985S-1995S.

49. Sniehotta FF, Luszczynska A, Scholz U et al. (2005) Discontinuity patterns in stages of the precaution adoption process model: meat consumption during a livestock epidemic. Br J Health Psychol 10, 221-235.

50. Harnack L, Story M, Martinson B et al. (1998) Guess who's cooking? The role of men in meal planning, shopping, and preparation in US families. J Am Diet Assoc 98, 995-1000.

51. Jansson S (1995) Food practices and division of domestic labor. A comparison between British and Swedish households. Sociol Rev 43, 462-477.

52. Williams P, Ridges L, Batterham M et al. (2008) Australian consumer attitudes to health claim - food product compatibility for functional foods. Food Policy 33, 640-643.

53. Dean M, Shepherd R, Arvola A et al. (2007) Consumer perceptions of healthy cereal products and production methods. J Cereal Sci 46, 188-196.

54. Arvola A, Lähteenmäki L, Dean M et al. (2007) Consumers' beliefs about whole and refined grain products in the UK, Italy and Finland. J Cereal Sci 46, 197-206. 